$\begin{array}{ll} & \text { Etnográfica } \\ \text { etnográfica } & \text { Revista do Centro em Rede de Investigação em }\end{array}$

Antropologia

vol. 17 (3) | 2013

Vol. $17(3)$

\title{
$O$ registo escondido num bairro em processo de realojamento: o caso dos hindus da Quinta da Vitória
}

The hidden transcript in a neighborhood's re-housing process: the case of Hindus in Quinta da Vitória

\section{Rita Ávila Cachado}

\section{(2) OpenEdition}

\section{Journals}

\section{Edição electrónica}

URL: https://journals.openedition.org/etnografica/3201

DOI: 10.4000/etnografica.3201

ISSN: 2182-2891

\section{Editora}

Centro em Rede de Investigação em Antropologia

\section{Edição impressa}

Data de publição: 30 outubro 2013

Paginação: 477-499

ISSN: 0873-6561

\section{Refêrencia eletrónica}

Rita Ávila Cachado, «O registo escondido num bairro em processo de realojamento: o caso dos hindus da Quinta da Vitória», Etnográfica [Online], vol. 17 (3) | 2013, posto online no dia 29 outubro 2013,

consultado o 11 fevereiro 2022. URL: http://journals.openedition.org/etnografica/3201 ; DOI: https:// doi.org/10.4000/etnografica.3201

\section{(c) (†) \&}

Etnográfica is licensed under a Creative Commons Attribution-NonCommercial 4.0 International License. 


\section{$\mathrm{O}$ registo escondido num bairro em processo de realojamento: o caso dos hindus da Quinta da Vitória}

\section{Rita Ávila Cachado}

Este artigo parte da etnografia realizada junto da população hindu de um bairro nas franjas da cidade de Lisboa. Tal como dezenas de outros conjuntos residenciais de construção informal, a Quinta da Vitória foi inscrita no Programa Especial de Realojamento (PER) e os seus habitantes seriam realojados em habitação social. Comparativamente com outros núcleos residenciais inscritos no PER, o processo da Quinta da Vitória levou mais tempo a ser concluído. Neste artigo procura-se descrever e analisar as formas como a população em causa reagiu, ao longo do processo de realojamento, a esta política social de habitação de grande envergadura no país. O objetivo central do artigo é explorar, através do caso em apreço, a conceptualização de James Scott (1990) sobre formas de resistência subtis, naquilo que o autor apelida registo escondido, e o desenvolvimento das suas componentes, até um registo mais público de resistência. Através da análise deste processo, espera-se ainda contribuir para uma melhor compreensão da aplicação das políticas sociais em Portugal.

PALAVRAS-CHAVE: registo escondido, políticas sociais, habitação, realojamento, diáspora hindu.

The hidden transcript in a neighborhood's re-housing process: the case of Hindus in Quinta da Vitória - This paper results from an ethnography among the Hindu dwellers of a neighborhood in the outskirts of Lisbon. As dozens of other informal settlements, Quinta da Vitória was one of the neighborhoods included in the Special Re-housing Program (PER), and its inhabitants would be resettled in social housing. Comparing with other similar settlements, the PER process at Quinta da Vitória was too long. In this paper I will describe and analyze the ways by which the Hindu residents responded to this huge social housing policy in Portugal, which was meant to end up with all "shanty towns". The main purpose of this paper is yet to explore James Scott's (1990) conceptualization on subtle resistance and about the hidden transcript, its forms, and development into public forms of resistance. The article is also expected to contribute to the larger debate about social policies in Portugal.

KEYWORDS: hidden transcript, social policies, housing, resettlement, Hindu Diaspora.

CACHADO, Rita Ávila (ritacachado@gmail.com) - Centro de Investigação e Estudos de Sociologia do Instituto Universitário de Lisboa (CIES-IUL), Portugal. 


\section{AS COMUNIDADES SUL-ASIÁTICAS TRANSNACIONAIS VÊM SENDO} analisadas do ponto de vista das dinâmicas associadas à diáspora e à integração nas sociedades de acolhimento. ' São exemplo disso os estudos mais reconhecidos sobre a diáspora hindu (Baumann 1998; Knott 2000; Vertovec 2000). Em Portugal, esse campo de estudos tem sido amplamente desenvolvido, sobretudo no que diz respeito aos hindus-gujaratis e às suas redes transnacionais em Moçambique, Índia e Reino Unido (Bastos e Bastos 2001; Lourenço 2010; Roxo 2010; Cachado 2012). ${ }^{2}$

Neste artigo o enfoque é feito sobre um grupo de hindus residentes num bairro que foi objeto da maior política de realojamento em Portugal até à data, o Programa Especial de Realojamento (PER). Trata-se do bairro Quinta da Vitória, na Portela de Sacavém, no concelho de Loures, localizado sobre a fronteira com a capital e inserido portanto na Área Metropolitana de Lisboa. Procura-se cruzar aqui o âmbito temático das migrações em Portugal com o da história da habitação. $\mathrm{O}$ facto conhecido de terem chegado às grandes cidades portuguesas centenas de milhares de imigrantes no final dos anos 1970, no contexto da independência das ex-colónias portuguesas, torna inevitável o cruzamento entre os dois âmbitos temáticos referidos, quer o ponto de partida se situe nos estudos sobre os migrantes, quer sobre os problemas da habitação em Portugal. No entanto, os estudos disponíveis optam na maioria por uma das perspetivas, resultando na análise da integração de uma determinada população imigrante sem examinar a problemática da habitação, ou na análise de um processo de realojamento sem detalhar etnograficamente os moradores. A apresentação da conjuntura em que surgem os estudos de habitação em Portugal feita nesta introdução servirá de pano de fundo para perceber melhor a situação de registo escondido analisada adiante.

Num estudo de Machado e Azevedo (2009) analisa-se a produção académica nacional sobre migrações e etnicidade, e os autores distinguem os temas e conceitos de maior e menor destaque na literatura, sublinhando as maiores recorrências e as maiores ausências. Apesar de as categorias selecionadas pelos autores serem passíveis de sobreposições, é relevante que entre os temas menos estudados se encontrem as "dinâmicas espaciais e territoriais" e a "pobreza e exclusão social", denotando uma falta no que toca à imigração cruzada com a habitação. ${ }^{3}$ Exceção recente a esta situação é o caso de um estudo coordenado

1 A pesquisa etnográfica para este artigo foi apoiada pela Fundação para a Ciência e a Tecnologia no âmbito de uma bolsa de doutoramento, e as reflexões teóricas foram desenvolvidas no curso do segundo triénio de um projeto de pós-doutoramento (FCT SFRH/BPD/47813/2008). Agradeço aos avaliadores deste artigo os comentários e chamadas de atenção e ao professor Brian Juan O’Neill, que me apresentou os conceitos de James Scott.

2 Qualquer um dos autores tem dedicado a maior parte do seu trabalho ao tema referido; incluíram-se aqui apenas as referências às publicações mais recentes neste domínio.

3 A título de exemplo quanto a possíveis sobreposições, refiram-se as categorias "retratos [continua] 
por Malheiros e Fonseca (201 1), que aborda precisamente o acesso à habitação pelos imigrantes. Também este artigo procura contribuir para colmatar essa falta. De todos os modos, os estudos sobre as comunidades imigrantes residentes em Portugal são vastos. Inicialmente resultantes de uma necessidade sociológica de caracterização das migrações e das populações imigradas, tornaram-se posteriormente fruto de análises de interpretação pós-colonial, isto é, que tecem interpretações de forma reflexiva sobre políticas de migração, e analisam o passado colonial e sua influência no presente das populações imigradas, entre outras abordagens cada vez mais detalhadas nas variáveis conjunturais.

Entre os estudos publicados que apresentam, descrevem e problematizam as populações imigradas em Portugal, destacam-se os trabalhos que representam as tentativas iniciais de caracterização global das comunidades de origem cabo-verdiana (Saint-Maurice 1997), os que se centram nas populações do Leste europeu (Baganha, Marques e Góis 2004), nos brasileiros residentes em Portugal (Machado 2006; Pinho 2012), ou nas populações sul-asiáticas (Bastos e Bastos 2001). O destaque para estes grupos deve-se quer à sua expressividade demográfica no início da década de 2000 (entre brasileiros e originários de diversos países do Leste europeu), quer à sedimentação cultural em Portugal (o caso dos cabo-verdianos), quer ainda ao interesse académico ao nível do estudo da transnacionalidade e diáspora (entre sul-asiáticos de várias origens nacionais). Antes e depois destes autores, muitas outras publicações contribuíram para conhecer melhor os imigrantes em Portugal. Voltando ao artigo de Machado e Azevedo, importa dizer que em 2009 estavam recenseadas 836 referências bibliográficas (2009: 9).

Claramente, a grande maioria dos estudos produzidos sobre estas populações não retrata apenas as populações em si, antes atravessa temáticas que lhes são subjacentes, como as condições de trabalho, a vida afetiva, a vida religiosa, entre outros grandes temas. Também o âmbito disciplinar se foi abrindo e cruzando; não só cada vez mais disciplinas das ciências sociais e humanas se dedicaram aos estudos de migrações, como as próprias disciplinas se foram atravessando cada vez mais. Uma parte dos estudos de migrações em Portugal cruza-se com os estudos urbanos, e é lá que surgem também os estudos de habitação.

Os estudos de habitação em Portugal foram férteis sobretudo nos anos 1990, situação que decorre também do facto de ter estado então em curso o Programa Especial de Realojamento. Provenientes de várias áreas de estudo, é a sociologia que produz mais trabalhos e maior variedade de abordagens neste campo (Baptista 1999; Freitas 2001; Nunes 2011), se bem que a arquitetura tenha sido a disciplina mais produtiva nos últimos anos (Farina 2001;

de populações migrantes e minorias étnicas" e “identidades e práticas culturais”, que surgem com um número de estudos muito díspar - 89 e 47 respetivamente -, estando o primeiro entre os temas mais estudados e o segundo entre os menos estudados (cf. Machado e Azevedo 2009: 13-15). 
Bandeirinha 2007; Lages 2011). A lacuna geral de trabalhos antropológicos nesta área não favorece análises do ponto de vista dos moradores. Muitos dos estudos aprofundados são, de resto, teses de mestrado e de doutoramento raramente publicados. O trabalho de Mónica Farina é disso exemplo, com uma tese de mestrado em Desenho Urbano, sobre a relação dos moradores de um bairro de habitação social com o espaço construído, assim como a tese de doutoramento de Marina Antunes em Antropologia Social, sobre os jovens de um bairro de habitação informal. ${ }^{4}$ Ainda assim, houve um período especialmente produtivo em estudos publicados em revistas da especialidade, que corresponde ao início do PER (Sociedade e Território, n. ${ }^{\circ} 20$ ) e ao auge da sua aplicação (Cidades, Comunidades e Territórios, n. ${ }^{\circ}$ 3).

Para o tema em consideração, podemos subdividir os estudos de habitação social em análises sobre dinâmicas socioculturais em bairros sociais e pesquisas sobre os processos de realojamento. Por sua vez, podemos subdividir estes em análise da satisfação residencial, análise social em geral, análise dos processos em si, e análise da vivência espacial por parte dos moradores. O facto de haver mais trabalhos sobre os bairros sociais do que sobre os bairros de onde provêm as populações realojadas provocou, entre outras lacunas, a ausência, até muito recentemente, de uma problematização aprofundada sobre as designações atribuídas pelas ciências sociais aos conjuntos residenciais em causa. A terminologia "bairros de barracas" foi posta em causa, por exemplo, por Ascensão (2011), ${ }^{5}$ seguindo o repto da terminologia inglesa informal settlement para substituir o termo mais impreciso de slum (Huchzermeyer e Karam 2006). Importa contudo referir que a designação "construção informal", tal como os outros termos, não é isenta de críticas; ela procura apenas ser mais explicativa do que as opções por "bairros de barracas" ou "bairros de lata", que remetem para a reprodução do estereótipo da cultura da pobreza associada a estes bairros (Wacquant 2005a, 2005b).

Este artigo surge no contexto de uma etnografia de caráter prolongado entre famílias hindus no bairro em apreço, iniciada no ano 2000 com um estágio

4 Recentemente, num livro que tive oportunidade de coorganizar (Cachado e Baía 2012), foram publicados alguns trabalhos de mestrado bem como primeiros resultados de pesquisas de doutoramento nesta área de estudos.

5 Importa referir que muitos autores rejeitaram claramente a tradução literal do francês bidonville por bairro de lata, e vários fazem referência à construção vernacular (termo mais utilizado pela arquitetura). No entanto, a designação inglesa informal settlements contribuiu para reparar lacunas na discussão sobre os termos utilizados para descrever conjuntos residenciais onde as casas são construídas pelos seus moradores. Assim, neste texto utiliza-se a designação "barracas" (entre aspas), escolha que decorre ainda do facto de, apesar da informalidade da construção, as casas serem quase sempre de alvenaria, e ainda no sentido de contribuir para a desconstrução de um termo usado abusivamente na literatura, que nem sempre corresponde à designação usada pelos seus moradores. Em trabalho anterior, tive também oportunidade de desenvolver uma pequena discussão sobre a terminologia associada a bairros degradados (Cachado 2012: 34-41). 
profissional no município de Loures. Deixada a ligação à Câmara, prossegui os estudos de mestrado e doutoramento mantendo o trabalho de campo na Quinta da Vitória. Durante algum tempo, a população continuou a identificar-me com a Câmara de Loures, pedindo-me informações sobre o realojamento e levando a maior parte das entrevistas informais para as questões da habitação, o que me conduziu a debruçar-me sobre o realojamento do bairro na pesquisa de doutoramento. Este artigo surgiu como possibilidade de desenvolvimento de uma das questões apenas afloradas no âmbito da tese. Importa referir que os dados patentes neste texto, quando não referenciados bibliograficamente, decorrem sobretudo do registo em diário de campo. ${ }^{6}$

\section{BAIRROS DE CONSTRUÇÃO INFORMAL}

No início dos anos 1990, estavam previstos dois grandes projetos de internacionalização do país: Lisboa seria Capital Europeia da Cultura em 1994 e seguir-se-ia a Expo 98. Nessa altura, os bairros de construção informal situados na fronteira de Lisboa com os concelhos limítrofes existiam em grande número. Não conviria à capital portuguesa ser palco daqueles encontros internacionais com tamanha proporção de bairros "de barracas".

Estes bairros da capital começaram a ser erigidos por migrantes portugueses provindos de diversas partes do interior do país à procura de melhores condições de vida (Fonseca 1990: 28), com visibilidade crescente a partir dos anos 1960, na mesma altura em que muitos portugueses optaram por emigrar para França e outros destinos europeus, encontrando inicialmente condições de habitação semelhantes às dos seus pares migrantes para a capital (Pereira 2009). A segunda fase do crescimento dos bairros em causa deu-se após as independências das ex-colónias e foi marcada por um aumento exponencial, uma vez que parte considerável dos recém-chegados não tinha possibilidades de adquirir habitações próprias nos subúrbios em expansão de Lisboa e Porto. Se uma parte da população em causa não teve essa oportunidade por motivos económicos, muitos outros lograram-no, contribuindo para o crescimento acentuado da metrópole e para o processo de suburbanização (Baptista 1999; Nunes 2011 ). Na verdade, estava-se perante um vazio da promoção legal da habitação, na sequência de um acordo entre o governo português e o FMI, que procurava desacelerar o endividamento provocado pelo excesso de créditos contraídos nos anos anteriores e que provocou a suspensão do lançamento de novos empreendimentos do setor público e cooperativo (Ferreira 1988: 60).

6 A prevalência e preferência pelo diário de campo como método de registo de dados etnográficos manteve-se ao longo de todo o trabalho de terreno na Quinta da Vitória. Esta escolha não resulta tanto de uma necessidade de identificação profissional (Jackson 1990: 6), mas é motivada sobretudo pela consistência dos dados nele contidos (Lederman 1990: 72) e pela sua capacidade interpretativa (Ottenberg 1990: 149). 
A construção civil fruto desta conjuntura é sobretudo a construção de bairros clandestinos, que permitia satisfazer as necessidades familiares face à ausência de alternativas (Soares, Ferreira e Guerra 1985: 75). Assim, os recém-chegados optaram por construir a sua própria casa (e.g. Quedas 1994: 56).

Além dos bairros excessivamente designados como "de barracas", os bairros que vieram mais tarde a ser designados áreas urbanas de génese ilegal (AUGI) (Cabral e Monteiro 2009) eram igualmente de construção informal, com diferenças relativamente aos primeiros. Os moradores procuraram reproduzir esquemas habitacionais preexistentes, como a vivenda unifamiliar com traços preponderantemente portugueses, em virtude da origem dos seus construtores. Além de uma diferença no acesso a materiais, que produziu nas AUGI um aspeto muito mais afim dos standards habitacionais em voga do que nos chamados bairros "de barracas", a principal diferença entre os dois tipos de bairros estava na organização da construção: as cooperativas de construção informais e as associações de moradores facilitavam a execução de planos de urbanização mínimos. Já quanto aos outros bairros, a construção informal aconteceu tanto ao nível da habitação como ao nível do bairro, provocando áreas urbanas de aspeto extremamente indesejável para os decisores políticos. De resto, o enquadramento arquitetónico fora dos esquemas clássicos europeus dos bairros urbanos tem conduzido a conceptualizações inovadoras do fazer cidade, no sentido em que aqueles conjuntos residenciais encerram uma cidade embrionária, "natural". Um ponto alto da literatura socioantropológica neste domínio está refletido na obra de Agier (2011), ao analisar o desenvolvimento dos campos de refugiados. As AUGI foram alvo de estudos sociológicos e arquitetónicos precoces (cf., por exemplo, Craveiro e Silva 1984) que, embora sem o devido reconhecimento científico, contribuíram para a legislação e aplicação de programas pensados a partir do conhecimento prévio e aprofundado dos contextos habitacionais que estavam em causa. ${ }^{7}$ A legalização e qualificação das AUGI foi assim preparada e, embora cada um dos processos tenha levado muito tempo (alguns núcleos habitacionais ainda estão em processo de qualificação), isso permitiu aos seus moradores não mudarem de local de residência e adquirirem melhores condições e infraestruturas no seu próprio bairro. Ao contrário, o outro tipo de bairros de construção informal foi inscrito no PER, que pretendia acabar com as "barracas", essa "chaga social ainda aberta" (nas palavras carregadas de sentido da lei do PER, DL n. ${ }^{\circ}$ 163/93, de 7 de maio) que urgia fechar. Face à urgência, a inscrição da maior parte dos bairros no programa de realojamento foi feita sem estudos prévios aprofundados sobre os

7 A maior parte dos estudos sobre bairros clandestinos que vieram a enquadrar-se na legislação das AUGI não foi publicada, estando o seu acesso muitas vezes reservado aos centros de documentação camarários ou do Instituto Nacional de Habitação (atual IHRU). 
conjuntos habitacionais visados, no que toca tanto à composição populacional como às condições de habitação.

No início dos anos 1990 houve contudo alguns estudos relativamente ao estado da habitação em Portugal; por isso, mesmo antes da legislação do PER, é realizado um recenseamento de muitos dos bairros "de barracas", nomeadamente o da Quinta da Vitória. O concelho de Loures encomendou o recenseamento das "barracas" do município ao Centro de Estudos Territoriais (CET 1992a, 1992b). Foi neste recenseamento feito em 1992 que os moradores ouviram falar em realojamento pela primeira vez. De resto, para a inscrição dos bairros no PER era necessário recensear as populações visadas, pelo que esse momento de inquirição acabou por funcionar como primeira porta de conhecimento dos bairros por dentro. Importa sublinhar que o esforço de recenseamento dos bairros a propósito do programa de realojamento então previsto originou, em muitos casos, o único registo exaustivo das populações residentes. ${ }^{8}$

A legislação do PER foi aprovada em 1993. O concelho de Loures assinou o contrato com o Instituto de Gestão e Alienação do Património Habitacional do Estado (IGAPHE) ${ }^{9}$ em 1995 e seria então que se daria início à sua implementação. De 1995 a 2000, o principal momento em termos da história do realojamento no bairro é a reinstalação de uma pequena parte da população (estima-se que 60 agregados familiares) no bairro camarário, a uma curta distância da residência anterior. Este realojamento parcial foi feito no âmbito das obras de restruturação das vias de acesso à ponte Vasco da Gama, e reúne dois aspetos interessantes. Primeiro, apesar de contemplar famílias inscritas no programa de realojamento, ele não é realizado no âmbito desse programa, mas sim em função das necessidades específicas da empresa Lusoponte (construtora da ponte Vasco da Gama). Segundo, sendo este o primeiro momento de realojamento do bairro Quinta da Vitória, ele faz-se para casas de apenas dois pisos, muito perto do bairro de origem. Os moradores realojados demonstraram uma satisfação residencial elevada (Cotrim et al., 2001) e os moradores ainda sem acesso a uma habitação social começam a ambicionar condições semelhantes de realojamento (Cachado 2000).

O PER, enquanto processo de realojamento de factum, começa a ser percetível pelos moradores da Quinta da Vitória no ano 2000, através da instalação de um Gabinete de Intervenção Local (GIL), uma figura administrativa pensada pelo município de Loures para executar o PER nos diferentes núcleos

8 No caso do bairro Quinta da Vitória, os recenseamentos posteriores, por ocasião das atualizações efetuadas aos bairros PER, visaram sobretudo as famílias já recenseadas, e as famílias residentes não inscritas no PER foram registadas em termos numéricos absolutos, mas não em termos de composição do agregado ou das condições habitacionais.

9 O IGAPHE e o INH foram entretanto extintos e integrados no IHRU, Instituto da Habitação e da Reabilitação Urbana. 
habitacionais do concelho. ${ }^{10}$ Coincidindo com os primeiros passos do PER no bairro, também uma política social estatal, o Plano Nacional de Luta Contra a Pobreza (PNLCP) surge no bairro através de algumas instituições com projetos aprovados. ${ }^{11}$ A observação etnográfica da aplicação dos projetos levou à perceção de que estas iniciativas, por um lado, contribuíram para aumentar as expetativas dos moradores relativamente à iminência do realojamento em habitação social e, por outro, acabavam por reproduzir um discurso de cultura da pobreza, provocando uma espécie de incorporação do estigma da pobreza, situação que não era assumida pelos moradores antes da realização destes projetos e do processo de realojamento (Cachado 2008a). Como veremos adiante, é essencialmente devido ao aumento das expetativas relacionadas com o realojamento que os moradores vão criando, primeiro, as suas próprias questões e, posteriormente, as suas próprias respostas face à demora na satisfação dessas expetativas. E é justamente no plano das respostas que surgirão elementos de resistência subtil, que só seria realmente percebida quando transformada em resistência pública.

Em trabalho aprofundado realizado anteriormente (Cachado 2012), um dos objetivos era analisar um processo de realojamento do ponto de vista da população visada e como esta foi reagindo, ao longo dos anos em que o processo de realojamento vinha sendo aplicado. Em traços gerais, que serão detalhados mais adiante, desde o início do programa de realojamento, em 1995, e até 2006, as famílias hindus lidaram com a aplicação do processo respondendo a uma execução formal e demorada de maneira informal, individual e familiar, sem uma ação conjunta através de uma associação, como acontecia no bairro Quinta do Mocho ou na Quinta da Serra (ambos próximos da Quinta da Vitória, na vizinha freguesia de Sacavém).

Em seguida, descreve-se a história do processo de realojamento no bairro e sua vivência pela população hindu, vista pelos vizinhos e pelos trabalhadores sociais como uma população pacífica. A título de ilustração, como ouvi no início do trabalho de campo por parte de técnicos de serviço social a trabalhar com esta população, "os hindus não dão problemas". Far-se-á depois uma descrição e análise crítica da forma como a população hindu do bairro Quinta da Vitória lidou com os diferentes momentos do processo de realojamento. Veremos como, após mais de dez anos de espera, o tipo de resistência da população passou de um registo escondido para um registo público, fazendo eco com a

10 À semelhança, por exemplo, do concelho de Cascais, que instituiu o Gabinete Autónomo para Programação e Gestão do PER (Freitas 2002). No concelho de Lisboa, foi a Gebalis (Gestão dos Bairros Municipais de Lisboa, EEM) que promoveu a gestão dos bairros de habitação social.

11 Os projetos desenvolvidos centraram-se em áreas que iam desde a ajuda alimentar, passando por cursos de língua portuguesa, até à promoção do emprego e da saúde (áreas de saúde materna e infantil, prevenção do alcoolismo e colaboração na recuperação da tuberculose). Foram levados a cabo por instituições do Estado e organizações privadas de solidariedade social, por associações de voluntários, etc. 
conceptualização feliz de James Scott (1990). Para isso, vejamos as formas como a população viveu o PER e como os técnicos que o aplicaram olharam para a população em causa.

\section{OS HINDUS DA PORTELA E O PROCESSO DE REALOJAMENTO}

A população hindu, à data do único recenseamento exaustivo realizado no bairro (em 1992), perfazia cerca de 50\% do total da população deste, configurando-se como maioritária naquele local. As demais populações do bairro diferenciavam-se entre portugueses de origem (quase 30\%) e africanos de vários contextos nacionais (mais de 20\%). Cabe referir que, apesar de provenientes de diversos contextos, a maioria dos residentes possuía a nacionalidade portuguesa, contribuindo para complexificar as habituais considerações sobre populações imigrantes, designação que, de resto, carece de sentido pleno tendo em conta a antiguidade da permanência em Portugal e a própria nacionalidade. ${ }^{12}$

As famílias hindus residentes em Portugal provêm sobretudo de Moçambique, de onde emigraram no início dos anos 1980. Esta proveniência deveria provocar o aumento da percentagem de população africana de $20 \%$ para $70 \%$. No entanto, a origem indiana, mais remota, destas famílias, pesa mais na heteroidentificação das populações do bairro (portugueses, indianos, africanos). A emigração destas famílias do Gujarate, no Noroeste do subcontinente indiano, para Moçambique ocorreu décadas antes no contexto do crescimento das cidades costeiras e do desenvolvimento do comércio colonial, não obstante o secular comércio no Índico ser anterior às relações coloniais, situação salientada por diversos autores, tanto ao nível da análise das relações com o contexto colonial português (Rita-Ferreira 1985; Leite 1996; Antunes 2001; Bastos 2005; Dias 2009), como ao nível das abordagens sobre a diáspora hindu-gujarati (Tambs-Lyche 1980; Vertovec 2000; Pearson 2001). ${ }^{13}$ A emigração que teve lugar nos anos 1980 para Portugal decorre do agravamento da situação política em Moçambique, que estava em guerra civil (Bastos e Bastos

12 Como é patente nesta área de estudos, a distinção entre origem e nacionalidade é útil para conhecer melhor as populações imigrantes provindas de ex-colónias portuguesas. Além disso, no caso dos hindus, com uma história de diáspora múltipla, em que a origem e a nacionalidade se misturam nos seus percursos migratórios, seria a distinção através da pertença religiosa que contribuiria para conhecer melhor em termos demográficos a população em causa. No entanto, os hindus estão acoplados à categoria "outras religiões não cristãs" nos censos nacionais, numa secção de preenchimento opcional como é a religião. A ineficácia deste aspeto nos censos portugueses foi já referida por Helena Vilaça (1999).

13 É raro encontrar entre os autores que analisam a diáspora sul-asiática trabalhos sobre as condições de acesso à habitação, mas é esse o caso do estudo de Tambs-Lyche (1980), onde se encontram semelhanças nas situações iniciais de sobreocupação residencial e de espera por uma habitação. 
2001), provocando a saída de milhares de famílias para Portugal entre 1978 e 1983, anos de maior efetivo de chegadas. ${ }^{14}$

A expetativa dos moradores face ao realojamento teve início com o recenseamento da população em 1992. Mas só aumentou realmente com a instalação do Gabinete de Intervenção Local em 2000 e com o início da construção de um bairro de grandes dimensões, o bairro social Dr. Alfredo Bensaúde, edificado justamente diante da Quinta da Vitória, para sul. Com um gabinete que aproximava finalmente os moradores das entidades que executavam o PER, os habitantes começaram a procurar respostas para as suas perguntas: para quando estava previsto o realojamento? O bairro em construção era para realojar os habitantes da Quinta da Vitória?

A construção do bairro social Dr. Alfredo Bensaúde, que começara no fim de 2000, fez levantar o boato entre os moradores de que estaria a ser construído para o realojamento das famílias residentes na Quinta da Vitória. Muito embora nas reuniões familiares os técnicos fossem esclarecendo os moradores de que nada havia sido indicado nesse sentido, parecia evidente para a população que, ao construir um bairro de habitação social, este só poderia estar destinado para os moradores da Quinta da Vitória. O bairro cresceu até aos seis andares ao longo de todo o comprimento este-oeste da Quinta da Vitória, sendo a evolução da obra permanentemente visível pelos seus residentes. De facto, a edificação de três quarteirões para 425 fogos habitacionais destinava-se ao PER; no entanto, não era dirigido às famílias visadas do concelho de Loures, mas sim às famílias residentes no concelho de Lisboa, provindas de diversos bairros de construção informal. Na verdade, o terreno onde se erigia a obra, apesar de contíguo à Quinta da Vitória, fica para lá da fronteira do concelho de Loures. ${ }^{15}$ Apesar desta situação, que parecia anular a possibilidade de os agregados familiares inscritos no PER de Loures serem realojados no bairro social vizinho, a Câmara Municipal de Loures teve a iniciativa de propor um protocolo entre os dois municípios para realojar uma parte da população da Quinta da Vitória, uma vez que o realojamento da totalidade das famílias seria impossível. Assim, em poucos meses, os processos de 100 agregados familiares foram transferidos para a Gebalis (Gestão dos Bairros Municipais de Lisboa, EEM), para que esta empresa municipal pudesse completar o processo de realojamento das famílias em causa. ${ }^{16}$

14 Esta forte imigração está de alguma maneira patente nos censos sobre religião, mesmo incompletos, onde podemos verificar que, entre 1981 e 1991, os praticantes de "outras religiões não cristãs" passam de um total de 3899 para 9455, representando cerca do dobro em termos percentuais face a outras religiões (de 3,37\% passam para 6,31\% do total das religiões não católicas em Portugal).

15 O bairro Quinta da Vitória foi construído sobre a linha de fronteira Loures-Lisboa que, à semelhança de uma grande parte da linha de fronteira entre Lisboa e os concelhos limítrofes, corresponde à antiga Estrada Militar.

16 Em entrevista, uma assistente social em funções no GIL na altura referia que o processo aconteceu "de repente" (12/04/2005). 
Para a população hindu, este último realojamento implicou, dois anos mais tarde, em 2004, o realojamento do templo. O templo, também de construção informal, foi realojado nos prédios de habitação social, embora num espaço mais pequeno, não cumprindo por isso na mesma medida todas as funções rituais que o outro espaço permitia. Importa contudo assinalar que, com um espaço de culto na mesma zona territorial, os hindus da Portela não alteraram em muito os seus percursos. Em geral, tanto as famílias realojadas como as famílias que ficaram a aguardar realojamento continuaram a frequentar o templo hindu Jai Ambé. ${ }^{17}$

As demolições decorrentes dos dois momentos de realojamento (1998 e 2002) provocaram alterações profundas no território, sendo uma das mais visíveis o surgimento de um espaço vazio entre os dois conjuntos residenciais, que os moradores de ambos os bairros foram aproveitando através da plantação de hortas, da realização de jogos de críquete e de futebol, churrascos, entre outras situações (Cachado 2008b). As autoridades separaram os espaços residenciais com uma rede, que foi sendo cortada e reposta ao longo dos anos, até que os acessos quotidianos foram assumidos com algumas aberturas permanentes. Hoje em dia, restam os pilares de sustentação do arame da rede, mas a circulação é feita livremente.

O processo de realojamento continuou para as famílias ainda à espera de nova morada. Em termos materiais, este processo implica um dossiê por família inscrita no PER, que é um trâmite burocrático, com muita documentação, fazendo jus à ideia de "pessoa burocraticamente definida" sugerida por Pierre Bourdieu (1990: 36) ao analisar dados que um banco acumula sobre os seus clientes, mas que adquire sentido também aqui, no seio de processos institucionais de relação entre poder local ou supralocal e destinatários de políticas sociais. Os pedidos de documentação por parte dos técnicos e as reuniões com os moradores sobre o processo de realojamento decorriam com dificuldades de comunicação de parte a parte. Estas mesmas reuniões e os pedidos cíclicos de documentação acentuaram por seu lado as expetativas das famílias que ficaram por realojar. De resto, toda a discursividade desta política de habitação social, desde as primeiras promessas inscritas na lei do PER ("vamos acabar com as barracas”), passando pela reiteração discursiva dessa intenção nas campanhas eleitorais, até à noção de senso comum de que o PER estava a dar casas aos pobres, conduziu à expetativa, de que já temos vindo a falar, de vir a ter uma casa.

17 Em 2004, isto era sobretudo verdade para os elementos mais velhos. Alguns, mais novos, relatavam que, após a transferência do espaço religioso, optaram por se dirigir mais frequentemente a outros templos (em Santo António dos Cavaleiros, Templo de Shiva, e no Lumiar, Templo de Radha-Krishna) para as festividades mais importantes do calendário hindu, justamente devido à composição etária dos devotos frequentadores dos templos. Recentemente, com o auxílio do Facebook, os elementos mais novos da família que gere o templo vêm impulsionando as atividades religiosas, trazendo de novo outros jovens para o Jai Ambé Mandir. 


\section{Vigilância sobre a população hindu?}

Os técnicos que executaram o PER nem sempre detinham todas as informações relativas ao processo de realojamento. O desdobramento burocrático dos gabinetes camarários fez com que, entre o poder executivo ao nível da vereação e a efetividade executiva ao nível dos gabinetes locais, houvesse limitações nas correntes de informação. Esta situação não é exclusiva do PER, esteve patente noutras políticas de habitação e vários autores o referem (Gros 1994: 81; Pereira 1963: 238; Baptista 2001: 76; Guerra 2001: 54). Por isso, era pouca a informação concreta que passava do gabinete para os moradores do bairro sobre o seu próprio futuro. Além disso, os técnicos raramente se deslocavam ao bairro, aumentando o distanciamento entre a população e a autarquia. As principais razões indicadas pelos técnicos para que raramente realizassem visitas ao terreno prendem-se com o excesso de trabalho burocrático e com o facto de serem poucos profissionais para muitos núcleos residenciais em processo de realojamento, corroborando Bonetti (1994: 21) quando refere que os técnicos têm uma representação da realidade através dos dossiês administrativos, o que aumenta a sua dificuldade de perceber os problemas dos habitantes.

Deste modo, a informação sobre o desenvolvimento do processo de realojamento tinha diferentes graus de perceção, de compreensão e de difusão. Se o município detinha a informação sobre as decisões, os técnicos que executaram o PER tinham dificuldade em explicar estes trâmites camarários à população. A situação agravou-se com o facto de haver poucas informações para fornecer à população, tendo em conta a escassez de terrenos e de verbas para o realojamento. ${ }^{18}$ À medida que os anos passavam no processo de realojamento, esta situação ficou cada vez mais patente. Se no início havia mais expetativas da parte do próprio município em cumprir os seus objetivos relativamente à habitação social, a diminuição das verbas municipais em 2004 refletir-se-ia naquela área com prejuízo para as famílias que aguardavam solução. Ainda assim, o processo continuou, como veremos, mas de facto as respostas já não poderiam ser de grande alcance a partir dessa altura. Nesse sentido, as promessas políticas relativas à habitação social ficariam comprometidas; não obstante, a população, que não estava a par de toda esta conjuntura, mantinha-se expectante.

Por isso, tal como relatado inúmeras vezes pelos moradores, referindo-se às visitas ao Gabinete de Intervenção Local, a população procurava informações

18 No Orçamento Retificativo de 2002 (Lei n. ${ }^{\circ}$ 16-A/2002, de 31 de maio) o nível máximo de endividamento das câmaras municipais foi reduzido para metade do que até então era possível. Apesar disso, havia exceções para o caso da habitação social, exceção essa que foi mantida na Lei n. ${ }^{\circ}$ 32-B/2002, de 30 de dezembro, que aprovou o Orçamento de Estado (OE) de 2003. No ano seguinte, o quadro legal restritivo relativamente ao endividamento das autarquias manteve-se (na Lei n. ${ }^{\circ}$ 107-B/2003, de 31 de dezembro, que aprovou o OE de 2004), revogando a exceção para a habitação social, o que levou a Associação Nacional de Municípios Portugueses a contestar o facto de a exceção se manter para as dívidas contraídas relativamente ao Euro 2004 e não para a habitação social. 
que raramente obtinha, o que aumentava a possibilidade de boatos sobre o desenrolar do processo de realojamento. Além disso, baseava-se naquilo que via. Por exemplo, ao ver o bairro Alfredo Bensaúde ser construído entre 2000 e 2002, como referi, a população considerou que aquele bairro seria para realojar a população da Quinta da Vitória. O facto de o bairro social pertencer geograficamente ao território do concelho de Lisboa não era percebido pela população. O protocolo entre as duas câmaras que deu lugar ao realojamento parcial foi um processo pouco entendido pelos moradores e conotado com as eleições naquele período - as eleições autárquicas em dezembro de 2001 e as legislativas em março de 2002 -, ou seja, os moradores sentiram que o realojamento parcial fora instigado por motivos eleitoralistas. Na prática, a verdade é que 100 famílias acabaram por ser ali realojadas. Nesse sentido, os boatos surtiram efeito ou, pelo menos, refletiriam uma verdade no futuro. Independentemente de fazerem parte do conjunto de famílias com a sorte de serem realojadas em 2002 ou de ficarem à espera sine die, todos os agregados familiares ficaram sujeitos a pedidos periódicos de entrega de documentação variada, atestando as pastas de arquivo dos processos familiares de habitação. ${ }^{19}$ A necessidade desta documentação, com pouca resposta a nível de realojamento efetivo, levou a população a perguntar-se relativamente a essa exigência.

No que diz respeito à população hindu, a análise dos processos familiares e os receios revelados por algumas famílias demonstraram que prevaleceram, por parte das entidades locais, ideias preconcebidas e generalizações culturais relativamente àquela população. As situações que levantavam suspeitas entre os trabalhadores sociais eram a duplicação de processos familiares entre bairros, a mobilidade residencial e o aumento do número de elementos por família. Por exemplo, como é patente em alguns processos familiares, os serviços interpretavam uma situação de um morador com o mesmo nome doutro morador noutro bairro PER como uma situação de duplicação propositada. Os casos de "duplicação", tal como é referido na própria documentação (juntam-se, nestes casos, fotocópias da legislação interna correspondente), referem-se a famílias que surgem duas vezes no recenseamento; no entanto, nas situações de duplicação de um nome em famílias diferentes, a dúvida também surgia. Importa esclarecer que duas pessoas podem de facto ter o mesmo nome, uma vez que os nomes hindus são compostos preferencialmente por apenas um nome próprio e pelo nome próprio do pai.

Num caso em concreto, que serve aqui de ilustração, uma família de origem indiana estava inscrita no recenseamento da Quinta da Vitória, e surgia também inscrita no recenseamento da Quinta da Holandesa, no Areeiro, em Lisboa. Esta situação vem sinalizada no processo familiar da família em causa

19 Para um total de 65 processos familiares analisados, somaram-se 952 fotocópias de documentos, perfazendo uma média de 15 documentos por agregado familiar, desde identificação, a certidões variadas. 
com a presença de uma lista de casos de "duplicação" realizada em outubro de 1994 e de um pedido feito pelo IGAPHE aos municípios para atualizar regularmente os dados das "duplicações" e que estes fossem enviados ao IGAPHE para centralizar a informação e para discriminar estas situações consideradas de oportunismo por parte das famílias. Esta prática por parte dos serviços decorre de uma necessidade de controlar os dados relativos à população candidata a realojamento, para que não fossem futuramente atribuídas duas casas em habitação social a uma mesma família. Outro exemplo tem a ver com uma família (que apenas saiu do bairro em 2012, sem realojamento) de quem as autoridades suspeitavam que detinha propriedade privada. Explicando doutra maneira, nesta família recaía a suspeita sobre o facto de um dos filhos do casal candidato a realojamento ter adquirido um terreno para posterior construção de habitação, conduzindo os serviços a exigir continuamente documentação das finanças e da segurança social, à família e às próprias instituições.

Mais abrangente para toda a população hindu é a suspeita de que as famílias detêm alternativa residencial noutros países, nomeadamente o Reino Unido, para onde, de facto, emigra uma parte da população que não obtém melhoria das condições de vida em Portugal. No terreno, evidenciam-se as viagens àquele país para fins rituais, para compras e para trabalho temporário em detrimento da procura de alternativa residencial. De resto, os contornos da diáspora hindu-gujarati extravasam a mobilidade residencial no caso de mudança permanente de país. Apesar disso, a documentação dos processos revela a frequência de viagens das famílias ao Reino Unido e, nesse sentido, o controlo dos serviços sobre estas viagens. Esta suspeita provém ainda da mobilidade residencial efetiva dentro do bairro. Há famílias que mudam de casa dentro do bairro, aproveitando casa de familiares que entretanto encontraram alternativa residencial noutros locais na Área Metropolitana de Lisboa (sobretudo em Chelas e em Santo António dos Cavaleiros) e, em casos raros, casas de famílias que emigram para o Reino Unido (que os técnicos procuram saber quem são, para as excluir do direito ao realojamento em habitação social).

Os processos familiares de habitação permitem ainda controlar o aumento do agregado, uma vez que as famílias crescem e solicitam a inserção de novos elementos no processo, para, em última análise, terem mais uma assoalhada na casa de habitação social. E, como não havia novos bairros sociais para realojar as famílias, esta situação representava uma dificuldade acrescida para os técnicos, que reagiam controlando mais. Assim, surgem nos processos certidões de casamento e de nascimento, que servem de justificação ao aumento ou diminuição do número de elementos por agregado familiar.

Em suma, subentende-se um controlo sobre a população, que se prende com a desconfiança de que muitas famílias hindus não necessitariam na realidade de serem realojadas, isto é, de que teriam alternativas de realojamento. Este controlo não corresponde necessariamente a uma persecução específica 
relativamente à população hindu da Quinta da Vitória; reflete antes uma saída burocrática encontrada pelos serviços para a ausência de respostas habitacionais no concelho de Loures. Dubois fala de formas semelhantes de controlo nos serviços públicos, salientando o argumento "das noções moles às decisões duras" (2009: 224), que basicamente significa que as leis, noções moles, podem ser (e são) interpretadas de várias maneiras pelos técnicos que as aplicam, mas essa mesma forma de as aplicar pode tornar-se um instrumento de controlo excessivo, as decisões duras, sobre as populações. Sublinhe-se que os técnicos, relativamente à população hindu, agiram apenas de acordo com as leis disponíveis e com o facto de não haver bairros sociais para realojar tantas famílias que mantiveram a expetativa de realojamento. Face à falta de tempo para conhecer de perto a população e o terreno, a edilidade incorreu em interpretações excessivas sobre as opções da população em causa.

\section{O REGISTO ESCONDIDO NA PORTELA}

A pouca informação sobre o processo de realojamento fornecida pelo município aos moradores visados e as dificuldades de comunicação geraram mal-entendidos por parte da população e controlo sobre esta por parte dos técnicos. E é aqui que entra James Scott, para nos ajudar a perceber as reações da população à situação de espera prolongada. O autor, proveniente da área da ciência política, ao realizar trabalho de campo junto dos trabalhadores nos arrozais malaios, descobre com surpresa a infrapolítica desta população através dos subterfúgios para escapar ao controlo excessivo dos patrões (Scott 1985), e elabora os primeiros traços daquilo que vem a chamar registo escondido, mas referindo-se inicialmente sobretudo a resistência subtil e a formas de infrapolítica. Posteriormente concentra-se na análise da dominação e das artes da resistência, epitomada no conceito de hidden transcript (Scott 1990), que em português vem sendo traduzido como registo escondido (e.g. Sobral 2004). Uma das ideias fortes que, embora não sendo nova, é ali sistematizada através da descrição de variadas situações históricas onde o fenómeno acontece, é que é a própria prática de dominação que cria o hidden transcript (Scott 1990: 27).

A partida, o conceito de hegemonia poderia servir para analisar os processos de infrapolítica, mas o problema com este conceito, defende Scott, é a assunção implícita de que a incorporação ideológica dos subordinados (isto é, o resultado das hegemonias) diminui o conflito social (1990: 77). A resistência, mesmo em contextos de ideologias hegemónicas fortes, sucede, mas está escondida e é preciso procurá-la nas "artes do disfarce político", desde a prática do anonimato, passando pela utilização de eufemismos, reclamar a terceiros, gerar boatos, até registos da própria cultura popular, que sintetizam formas de resistência subtil, como os contos sobre impostores, a inversão simbólica, os rituais de Carnaval. 
O contexto em apreço neste artigo é um terreno fértil para a resistência subtil, para o registo escondido como Scott o problematiza. Sem na verdade estarem na situação de poder direto, os serviços camarários representavam, para a população, o poder. Os moradores hindus representam aqui o grupo dominado, numa continuidade pós-colonial com a situação de dominação anterior. Nesta secção, veremos como as formulações de James Scott têm eco nas reações dos moradores hindus do bairro Quinta da Vitória face aos desenvolvimentos do processo de realojamento.

Os boatos e as estratégias para manter o direito ao realojamento são um sinal de que há registo escondido na forma de reagir a um processo de realojamento complexo. O que Scott diz sobre o registo escondido pode aplicar-se às dinâmicas da população hindu relativamente ao processo de realojamento no bairro até 2006. Na verdade, as famílias hindus desenvolveram táticas informais no sentido de manterem o direito ao realojamento em habitação social. No início dos anos 2000, no auge da aplicação do PER, fizeram-no (i) procurando dar razões aos técnicos de serviço social para a sua necessidade especial de que o processo fosse acelerado; (ii) entregando documentos relativos a problemas de saúde de um ou mais elementos dos agregados familiares; (iii) procurando uma atenção especial por parte dos técnicos. A (iv) utilização de boatos e bodes expiatórios (duas formas de registo escondido elencadas por Scott) foi também prática corrente.

Todas estas formas de resposta, mas sobretudo as primeiras três, caracterizam-se pela sua individualidade, uma vez que não são feitas em conjunto pelos moradores. Cada família, cada indivíduo deslocava-se ao Gabinete de Intervenção Local para expor o seu caso. A última referida, boatos e bodes expiatórios, foi sendo percebida ao longo do trabalho de campo. A abundância de frases ditas pelos moradores começadas com "dizem que", "parece que agora é que vai ser...", "ouvi dizer", atesta-o. A referência aos bodes expiatórios prende-se com a recorrência de situações em que a Câmara Municipal, personificada nos técnicos do Gabinete de Intervenção Local, era acusada de ineficácia no processo de realojamento. Uma outra forma de bode expiatório surgiu no bairro na forma de culpabilização dos vizinhos. Alguns moradores queixaram-se aos técnicos de que outras famílias estavam a subalugar casas do bairro de habitação social e que famílias a aguardarem alojamento social encontravam alternativa residencial e alugavam a sua casa no bairro Quinta da Vitória, em vez de comunicarem diretamente que já não necessitavam de alojamento social. Desta forma, torna-se manifesto que "[as] reações são tanto mais elaboradas quanto mais elaborado for o sistema de dominação que as precede" (Scott 1990: 111).

Relativamente ao caso analisado antes, de suspeitas dos técnicos sobre a população hindu, recorro a Scott quando diz que o controlo sobre as populações através da vigilância agudiza a subordinação e procura eliminar hipóteses 
de resistência, mas isso não quer dizer que ela não suceda (Scott 1990: 83). Ouvi por diversas vezes que "é melhor não fazer barulho", no sentido de que a população hindu tinha a perceção de que seria preferível não forçar o processo, e preferiam fazê-lo individualmente.

Sobre a informalidade das ações pela manutenção do direito ao realojamento, uma outra citação de Scott faz aqui sentido: "Só porque uma parte dos protestos são reivindicações de que os dominantes cumpram o seu papel, não deixam de ser reivindicações e de constituir uma massa crítica contra o poder dominante" (1990: 92). Explicando melhor, no bairro ouvi por diversas vezes a seguinte formulação sobre o processo de realojamento: "Dizem que vão fazer e depois não fazem nada e é só promessas”, o que reflete um tempo de espera que separa o recenseamento da população a habitar em barracas em 1992 e os realojamentos dez e quinze anos depois. Deste modo, creio ser apropriado dizer que estas formas de registo escondido ocorrem justamente em prol da manutenção do direito ao realojamento, para que se cumpra aquilo que um dia lhes foi prometido.

\section{Da resistência subtil à resistência pública}

Além destas ações informais e individuais, naquilo que a certa altura na investigação considerei constituir-se como um habitus na forma de agir sobre o contexto sociopolítico a acontecer sobre esta população (Cachado 2005), no ano de 2006, os acontecimentos acabam por pôr em causa um argumento teórico sobre a população estudada. Os hindus da Quinta da Vitória pareciam encaixar-se bem na formulação de Scott de resistência subtil e, se o trabalho de terreno tivesse terminado antes dos acontecimentos relatados em seguida, os argumentos de Scott aplicar-se-iam à Quinta da Vitória apenas pela metade. $\mathrm{Na}$ verdade, de certa forma inesperadamente, isto é, para quem vinha observando apenas registos escondidos na formulação de Scott, em 2006 a população hindu envolveu-se num processo de luta formal, pública, pelo acesso ao realojamento. Clarificamo-lo em seguida.

Alarga-se aqui o foco para uma escala mais lata e conta-se resumidamente o contexto social em meados de 2006 relativamente aos bairros degradados que aguardavam um desfecho para os seus processos de realojamento. No início do ano de 2006 forma-se a Plataforma Artigo 65 - Direito a Habitar, que era uma plataforma de associações pelo direito à habitação nas suas diversas modalidades. Uma das associações componentes era a Solidariedade Imigrante (Solim), que há menos de um ano formara um grupo de trabalho chamado Direito à Habitação, seguindo a linha política e de ação do Droit au Logement francês, cuja estratégia passava pelas ações com visibilidade mediática. Este grupo de trabalho procurava motivar os moradores a lutarem pelo direito ao realojamento em vários bairros em condições semelhantes às da Quinta da Vitória, sobretudo no verão desse ano, que foi quando houve mais demolições 
de casas de famílias com situação irregular no que dizia respeito ao processo de realojamento.

Na mesma altura, a nível local, na Quinta da Vitória, a Câmara Municipal via-se sem alternativas para os moradores que continuavam a aguardar pelo desfecho do PER e aceitou a proposta do proprietário que passava por indemnizar as famílias. Deste modo, a indemnização das famílias coincidiu com o clímax de luta da Plataforma Artigo 65 e do grupo Direito à Habitação.

A Solidariedade Imigrante no bairro começou por fazer reunióes de motivação para a luta pelo direito à habitação. As pessoas reagiram inicialmente de forma hesitante e desconfiada. Foi um processo curioso quando ganharam confiança. Muitas pessoas falaram em público pela primeira vez sobre as suas preocupações relativamente à habitação. Surgiram frases, vindas de moradores hindus que compareceram a esta reunião, como "se alguém quiser lutar sozinho não consegue" e "a união faz a força”. É importante dizer que a abordagem das ativistas ${ }^{20}$ foi diferente da de outras pessoas que se deslocavam ao bairro para realizar os seus projetos. Foi uma intervenção mais aberta na forma de dialogar, rejeitando posicionamentos de tipo assistencialista, segundo as próprias, o que terá contribuído para a participação da população. E sobre a situação de falar pela primeira vez, parece-me que a afirmação seguinte de Scott faz também todo o sentido: a declaração aberta do registo escondido é experienciada como um momento em que finalmente se disse a verdade (Scott 1990: 208).

Seguiram-se outros momentos de registo público da resistência, de envolvimento político na luta pela manutenção do direito à habitação. Destacam-se uma ação de luta no bairro contra a demolição de casas de famílias que estavam em situação irregular no PER e a participação da população numa manifestação no centro de Lisboa. Na primeira, com a colaboração do grupo Direito à Habitação e da Plataforma Artigo 65, algumas famílias defenderam as casas da demolição subindo aos telhados. Ao fim da manhã o processo de demolição de casas de famílias foi interrompido. Já sobre a manifestação, participaram poucos moradores hindus, mas ao falar com os poucos participantes, destacase o caso de uma mulher que dizia ser a primeira vez que se deslocou ao centro da cidade. É importante notar que este tipo de participação pública representa a vida política dos subordinados que, como diz Scott, raramente é vista como vida política (Scott 1990: 198).

20 A utilização do feminino reflete o testemunho no terreno de que o grupo de trabalho Direito à Habitação da Associação Solidariedade Imigrante na Quinta da Vitória (e noutros bairros) se fazia representar sobretudo por mulheres. Da população, a forte participação das mulheres é também de realçar. No entanto, as questões de género abordadas por uma vasta produção académica, não ignorada por mim, não são problematizadas teoricamente neste trabalho. 


\section{CONSIDERAÇÕES FINAIS}

Com o conceito de hidden transcript, James Scott defende que as várias formas de resistência subtil por parte de uma população em alguma situação de subalternidade vem um dia a tornar-se resistência pública, num registo mais aberto. Muitas vezes, os casos evidentes de registo escondido que se transformam em registo público referem-se a situações que já ocorreram e, nesse sentido, podemos interpretá-las a posteriori como tal. Raramente existe a oportunidade, como tive, no caso desta etnografia com os hindus da Quinta da Vitória, de observar uma situação evoluir para outra. Até 2006, o trabalho de campo no bairro demonstrava que os moradores hindus respondiam informalmente à demora na execução do processo de realojamento. Mas apesar de ter presenciado as diversas fases, fiquei surpreendida com a revolta (aparentemente) repentina dos moradores hindus, tal como, seguindo Scott, se surpreendem muitas vezes os cientistas sociais quando observam processos de resistência pública (1990: 224).

Contudo, não é certo que a descrição desta situação se enquadre num caso de resistência tout court. De resto, a formulação de James Scott, nos seus principais argumentos (1985, 1990, 1998), o que indicia é a importância de olhar para os subordinados (independentemente do grau de subordinação) e conhecer os seus quotidianos para promover políticas ajustadas e, em última análise, prevenir novos boatos, sussurros, eufemismos, invenções, sobre os poderes instituídos, que pioram os canais de comunicação já deteriorados ou mesmo inexistentes. O registo, primeiro escondido e depois aberto, das respostas dos moradores hindus ao PER inacabado no seu bairro evidencia antes um conjunto de adaptações, mais do que de resistências, à situação vivida de forma prolongada. Outro autor de nome Scott (1997), numa análise sobre o pós-colonialismo, defende que as populações colonizadas não se limitaram a defender-se dos colonizadores durante os períodos conturbados das independências, mas sim que as populações sempre fizeram a sua história; a diferença é que não estava lá ninguém de fora para o contar, embora, note-se, o "dar voz" não seja o objetivo central deste artigo. O que importa aqui é que aquilo que pode ser facilmente lido a posteriori como resistência, é mais difícil ser lido como tal quando em presença dos acontecimentos.

Neste artigo procurei descrever a situação de vivência prolongada por parte de uma população que reagiu de variadas formas a uma política social de grande envergadura, como foi o PER. A expetativa e esperança iniciais, potenciadas pelos discursos da própria lei do PER e pela presença inicial de trabalhadores sociais no bairro, foram sendo substituídas pela quase ausência de informação clara sobre o processo de realojamento e, ao mesmo tempo, por um acréscimo das exigências burocráticas face à população que aguardava por uma habitação social. O desequilíbrio entre a falta de informação e a exigência do lado dos 
executores gerou um conjunto de respostas por parte da população em causa. Olhando mais atentamente para essas respostas, torna-se percetível, não sem surpresa quando os registos se tornam públicos, que esta população transnacional, adaptando-se a novos contextos nacionais e urbanos praticamente de geração em geração, desenvolveu as suas próprias artes de resistência.

\section{BIBLIOGRAFIA}

AGIER, Michel, 201 1, Antropologia da Cidade: Lugares, Situações, Movimentos. São Paulo, Editora Terceiro Nome.

ANTUNES, Luís Frederico Dias, 2001, O Bazar e a Fortaleza em Moçambique: A Comunidade Baneane do Guzerate e a Transformação do Comércio Afro-Asiático (1686-1810). Lisboa, FCSH-UNL, tese de doutoramento.

ASCEnSÃO, Eduardo, 2011, The Post-Colonial Slum: A Geography of Informal Settlement in Quinta da Serra, Lisbon 1970s-2010. Londres, King's College, tese de doutoramento.

BAGANHA, Maria Ioannis, Pedro MARQUES, e José Carlos GÓIS, 2004, "Novas migrações, novos desafios: a imigração do Leste europeu", Revista Crítica de Ciências Sociais, 69: 95-115.

BANDEIRINHA, José António, 2007, O Processo SAAL e a Arquitectura no 25 de Abril de 1974. Coimbra, Imprensa da Universidade de Coimbra.

BAPTISTA, Luís Vicente, 1999, Cidade e Habitação Social. Oeiras, Celta Editora.

BAPTISTA, Luís Vicente, 2001, "Cidades e políticas sociais de habitação: armadilhas conceptuais e metodológicas”, Cidades, Comunidades e Territórios, 3, 71-81.

BASTOS, Susana Trovão Pereira, 2005, “'Our colonizers were better than yours': identity debates in greater London”, Journal of Ethnic and Migration Studies, 31 (1): 79-98.

BASTOS, Susana Trovão Pereira, e José Gabriel Pereira BASTOS, 2001, De Moçambique a Portugal: Reinterpretações Identitárias do Hinduísmo em Viagem. Lisboa, Fundação Oriente.

BAUMANN, Martin, 1998, “Sustaining little 'Indias': Hindu diasporas in Europe”, em Gerrie Ter Haar (org.), Strangers and Sojourners: Religious Communities in the Diaspora. Leuven, Peeters Publishers, 95-13.

BONETTI, Michel, 1994, "Revalorisation des quartiers en crise: de la réhabilitation à la gestion urbaine intégrée”, Sociedade e Território, 20: 17-25.

BOURDIEU, Pierre, 1990, "Un contrat sous contrainte", Actes de la Recherche en Sciences Sociales, 81 (2): 34-51.

CABrAl, Paula, e Maria João MONTEIRO (orgs.), 2009, Actas da Conferência Áreas Urbanas de Génese Ilegal: Projectos para a Legalização de Um Sonho. Cascais, Câmara Municipal de Cascais.

CACHADO, Rita d'Ávila, 2000, Vivências na Vitória: Esboço de Caracterização da Comunidade Hindu da Quinta da Vitória. Loures, Câmara Municipal de Loures, relatório de estágio profissional. 
CACHADO, Rita d'Ávila, 2005, "Um bairro em vias de realojamento: estratégias de resistência e de adaptação aos processos burocráticos”, em Política Cultural: Iniciativas de las Administraciones, Respuestas de los Administrados, X Congreso de Antropología, Sevilha, Fondación El Monte, FAAEE, AAA, 121-136.

CACHADO, Rita d'Ávila, 2008a, "Poverty political discourse and its effects: Portuguese Hindus between shanty town and the social housing estate", Arquivos da Memória, n. s., 3: 39-57.

CACHADO, Rita d'Ávila, 2008b, "Entre as casas e o templo, a rua: comunidade hindu e interacções de bairro", em Graça Índias Cordeiro e Frédéric Vidal (orgs.), O Lugar da Rua: Espaço, Tempo, Sociabilidade. Lisboa, Livros Horizonte, 129-142.

CACHADO, Rita d'Ávila, 2012, Uma Etnografia na Cidade Alargada: Hindus da Quinta da Vitória em Processo de Realojamento. Lisboa, Fundação Calouste Gulbenkian e Fundação para a Ciência e a Tecnologia.

CACHADO, Rita Ávila, e João BAÍA, 2012, Políticas de Habitação e Construção Informal. Lisboa, Mundos Sociais.

CET - Centro de Estudos Territoriais, 1992a, Perfil Social e Situação Habitacional da População Residente em Bairros de Barracas do Concelho de Loures. Lisboa, CET.

CET - Centro de Estudos Territoriais, 1992b, Levantamento e Caracterização Urbanística dos Bairros de Barracas do Concelho de Loures. Lisboa, CET.

COTRIM, Ana, Ana RUNA, Lisete ALMEIDA, Luís WEMANS, e Teresa AMOR, 2001, "Impactes sociais e urbanos da ponte Vasco da Gama: economia local, habitação e condições de vida em avaliação", Cidades, Comunidades e Territórios, 2: 99-110.

CRAVEIRO, Maria Teresa, e Fernando Nunes da SILVA, 1984, "Serra da Silveira: urbanizar com a população", Sociedade e Território, 1: 61-68.

DIAS, Nuno, 2009, Remigração e Etnicidade: Mobilidade Hindu no Trânsito Colonial entre a África de Leste e a Europa. Lisboa, Instituto de Ciências Sociais, tese de doutoramento.

DUBOIS, Vincent, 2009, “Towards a critical policy ethnography: lessons from fieldwork on welfare control in France”, Critical Policy Studies, 3 (2): 219-237.

FARINA, Mónica, 2001, Por Uma Antropologia do Habitar: Projecto e Quotidiano Num Bairro de Habitação Social em Lisboa. Lisboa, ISCTE, tese de mestrado.

FERreIRA, António Fonseca, 1988, "Política(s) de habitação em Portugal”, Sociedade e Território, 6: 54-62.

FONSECA, Maria Lucinda, 1990, População e Território: Do País à Área Metropolitana. Lisboa, Faculdade de Letras da Universidade de Lisboa, tese de doutoramento.

FREITAS, Maria João, 2001, "Recentramento do olhar nas questões da habitação: territórios relacionais generativos”, Cidades, Comunidades e Territórios, 3: 21-39.

FREITAS, Maria João, 2002, "Aprendizagens num percurso de autonomias e poderes: o processo de realojamento em Cascais”, Cidades, Comunidades e Territórios, 4: 19-32.

GROS, Marielle Christine, 1994, “Pequena' história do alojamento social em Portugal”, Sociedade e Território, 20: 80-90.

GUERRA, Isabel, 2001, "Intervenções face à exclusão social urbana: uma luta inglória?", Cidades, Comunidades e Territórios, 2: 47-56.

HUCHZERMEYER, Marie, e Aly KARAM (orgs.), 2006, Informal Settlements: A Perpetual Challenge? Cidade do Cabo, UCT Press.

JACKSON, Jean E., 1990, “II am a fieldnote': fieldnotes as a symbol of professional identity”, em Roger Sanjek (org.), Fieldnotes: The Makings of Anthropology. Ithaca e Londres, Cornell University Press, 3-33. 
KNOTT, Kim, 2000, "Hinduism in Britain”, em Harold Coward, John Hinnels e Raymond Williams (orgs.), The South Asian Diaspora in Britain, Canada and the United States. Nova Iorque, State University of New York Press, 89-10.

LAGES, Joana Pestana, 2011, À Espera no Bairro do Talude Militar: Reflexões sobre o Direito à Habitação. Lisboa, Faculdade de Arquitetura da Universidade Técnica de Lisboa, tese de mestrado.

LEDERMAN, Rena, 1990, "Pretexts for ethnography: on reading fieldnotes”, in Roger Sanjek (org.), Fieldnotes: The Makings of Anthropology. Ithaca e Londres, Cornell University Press, $71-91$.

LEITE, Joana Pereira, 1996, "Diáspora indiana em Moçambique”, Economia Global e Gestão, s.n.: $67-108$.

LOURENÇO, Inês, 2010, "Anthropological perspectives on female identity: the Hindu Diaspora in Portugal", The International Journal of Interdisciplinary Social Sciences, 5 (5): 143-150.

MACHADO, Fernando Luís, e Joana AZEVEDO, 2009, "A investigação sobre imigração e etnicidade em Portugal: tendências, vazios e propostas", Migrações, 4: 7-31.

MACHADO, Igor José de Renó (org.), 2006, Um Mar de Identidades: Imigração Brasileira em Portugal. São Carlos, Edufscar.

MALHEIROS, Jorge, e Lucinda FONSECA (orgs.), 201 1, Acesso à Habitação e Problemas Residenciais dos Imigrantes em Portugal. Lisboa, ACIDI.

NUNES, João Pedro Lopes de Oliveira Silva, 2011 , Florestas de Cimento Armado: Os Grandes Conjuntos Residenciais e a Constituição da Metrópole - Lisboa, 1955-1981. Lisboa, Fundação Calouste Gulbenkian e Fundação para a Ciência e a Tecnologia.

OTTENBERG, Simon, 1990, "Thirty years of fieldnotes: changing relationships to the text", em Roger Sanjek (org.), Fieldnotes: The Makings of Anthropology. Ithaca e Londres, Cornell University Press, 139-160.

PEARSON, Michael, 2001, The Indian Ocean. Londres, Routledge.

PEREIRA, Raul da Silva, 1963, "Problemática da habitação em Portugal - 2", Análise Social, I (2): 225-269.

PEREIRA, Victor, 2009, “L'émigration clandestine portugaise vers la France et les paradoxes de l'intégration européenne”, Sociétés Politiques Comparées, 19, disponível em <http://www .fasopo.org/reasopo.htm\#revue> (última consulta em 27/9/2013).

PINHO, Ana Filipa, 2012, Transformações na Emigração Brasileira para Portugal: De Profissionais a Trabalhadores. Lisboa, ISCTE-IUL, tese de doutoramento.

QUEDAS, Maria João, 1994, "Expectativas habitacionais e coexistência espacial de grupos étnicos: inquérito à população mal alojada do concelho de Loures”, Sociedade e Território, 20: 55-62.

RITA-FERREIRA, António, 1985, “Moçambique e os naturais da Índia portuguesa”, Actas do II Seminário Internacional de História Indo-Portuguesa. Lisboa, IICT, s.p.

ROXO, Pedro, 2010, "Negotiating identity through expressive culture: Hindu-Gujarati Portuguese in Mozambique, Portugal and England", em Susana Trovão e Marta Vilar Rosales (orgs.), Das Índias, das Gentes: Movimentos e Pertenças Transnacionais. Lisboa, Edições Colibri, 169-206.

SAINT-MAURICE, Ana, 1997, Identidades Reconstruídas: Cabo-Verdianos em Portugal. Oeiras, Celta Editora.

SCOTT, David, 1997, "Le colonialisme”, Revue Internationale des Sciences Sociales, 154: 561-570 . 
SCOTT, James C., 1985, Weapons of the Weak: Everyday Forms of Peasant Resistance. Westford, MA, Yale University Press.

SCOTT, James C., 1990, Domination and the Arts of Resistance: Hidden Transcripts. New Haven e Londres, Yale University Press.

SCOTT, James C., 1998, Seeing like a State: How Certain Schemes to Improve the Human Condition Have Failed. New Haven e Londres, Yale University Press.

SOARES, Luís Bruno, António Fonseca FERreIRA, e Isabel Pimentel GUERRA, 1985, "Urbanização clandestina da Área Metropolitana de Lisboa”, Sociedade e Território, 3: 67-77.

SOBRAL, José Manuel, 2004, "Memoria social, identidad, poder y conflicto", Revista de Antropología, 13: 137-159.

TAMBS-LYCHE, Harald, 1980, London Patidars: A Case Study in Urban Ethnicity. Londres, Routledge.

VERTOVEC, Steven, 2000, The Hindu Diaspora: Comparative Patterns. Londres, Routledge.

VILAÇA, Helena, 1999, "Alguns traços acerca da realidade numérica das minorias religiosas em Portugal”, Lusotopie, 1999: 277-289.

WACQUANT, Loïc, 2005a, "Les deux visages du ghetto: construire un concept sociologique", Actes de la Recherche en Sciences Sociales, 160: 4-21.

WACQUANT, Loïc, 2005b, “Une ville noire dans la blanche': Le guetto étasunien revisité,, Actes de la Recherche en Sciences Sociales, 160: 22-31. 